\title{
Cogitate Marketization Development of Promoting Community Service
}

\author{
Yingxia Liu \\ Marx Institute of Dalian University Liaoning Dalian, 116622 \\ Lyx111505@sina.com
}

Keywords: Community; Community service; Marketization

\begin{abstract}
To implement the community service market need do a good job in strategic planning, basing on the government's service function design market development ideas, to Construct of market development model. The pattern of community service marketization should at least include: The marketization of service subject, the quality of social workers and demand of marketization, the source of funds and operation of the marketization, evaluation and supervision mechanism of the marketization.
\end{abstract}

\section{Research Background and Current Situation}

Research Background. Since 1980s, the government's administrative reform has caused the change of the social governance mode, the core of which is to push some public services to the market, and to explore the effect of the social operation of the market. Since the middle of 1990s, in a stable situation of Chinese society of development, the resident's life and the social order, the status and function of community construction and community work have become increasingly prominent. Contradictions between unified government management under the planned economy system and the development of public services under the condition of market economy make the contradictions between the reality of the social demand and the government management becoming more and more serious, The contradiction between the important public service responsibility and the relative lack of administrative resources is becoming increasingly serious, which has emerged the innovated problem of community management system and service model, and the construction of what kind of community service market model as part of the public service reform has become a hot topic.

At present, our country's community service should discuss "a diversified, market-oriented management model participated in by the various functional departments of the community, a variety of social organizations and community residents ". The community service is an important part of public service, so based on the discussion of community service marketization pattern playing an important role for development of government public service; government through the purchase of a variety of public services can promote the mode of community service innovation, and promote the development of public services.

A Theoretical Study on the Marketization of Public Service at Home and Abroad. About the research on public service market, foreign academic circles pay close attention to the core target is to improve administrative efficiency, to enhance the quality of public services. Scholars have argued that the market competition mechanism should be introduced into the field of public service supply in order to change the government function better and faster; government like market is considered to be an effective model of government governance, which requires the government to clear their identity and status in the reform, to relax the control of the market, to encourage social participation. For example Osborne and Gambler affirmed the importance of community participation in social development, and points out that community participation is to create opportunities for all members of the community and allow wider public to positive contribution and influence the development process, and equally share the fruits of development, and put forward the concept of "enterprise government", and located the functions of the government, and confirmed the importance of community participation in the development of society; Peters put forward four modes of public service governance, and pointed out that the service type government is the most clear development trend. E. S. Savas highly defined the role of the market, think this is not only a 
good management tool, but a for the social governance basic strategy, and pointed out that government public management reform is the essence of public service marketization, is the distinction between the service providers and service production is its core.

Based on the theory of western public service choice theory and public governance theory, the domestic scholars carry out community service marketization field of study, and learn from the western government to the public service marketization as the main content and the main content of administrative reform. Scholars agree that the government as single service corpus has been difficult to meet the demand for public service diversification, the public service work must go "passing the administrative", to absorb the diversified the main body, such as non-governmental organizations, social organizations and volunteer team, to better enhance the service quality and efficiency. Such as Professor Wang Puqu on the basis of the analysis of the three main framework, focus on the government to buy public services to social organizations; Rao Huilin pointed out that urban management has five functions: the guiding function, normative functions, management functions and service functions and management functions. In the implementation of the market we should clearly posit the functions of the government; Zhou Zhiren emphasized the difference between government responsibility marketization and service provision mechanism marketization Proposed to make full use of all kinds of social forces to absorb international experience, through the introduction of competition mechanism to improve public service efficiency, enhance the level of service and quality of service, et

\section{The Connotation of Community Service Marketization}

Community as a basic unit of public service, is a microcosm of society, is one of the basic places for people to participate in social life, people in the community will achieve a certain public welfare and public service satisfaction. Community service "is under the government support and funding, which is launched and organized members by community service officers, Utilizing and developing community resources, to carry out the welfare and welfare of the social services and the convenience of living services to meet the needs of the community members of the process of life.

To provide public services and public goods in the community, Need to attract a wide variety of social subjects to participate in, On the original public services provided by the government directly to sort out some of the items can be purchased, tender or direct funding provided by the project to a qualified social services completed, Thus form a partnership between the government and the various social organizations, namely the realization of the market operation of some public services, which requires to explore the market model of community services.

Community service marketization is refers to by the market to lead the development of community service, some form a free market by the community with unprofessional and high cost than other social organizations, relying on competition mechanism, in the planning and supervision of the government. Through a variety of ways to buy or cooperate to complete the public service and public goods, that is, the community should do something and not do something with a variety of services ".

Government Functions to Promote Community Service Marketization. The government's excessive public service will cause the problem of "offside", it is difficult to mobilize the enthusiasm, but government cannot be "Absence", and can't push all responsibility of public service to the market. Therefore, the government's promising; there is a basic standard for the government to provide public services.

In the discussion of the basic mode and thinking of the community service market, we should recognize the basic status of the government, and summarize the functions that the government should play in the following five aspects:

Leading function, this function is mainly to guide the direction of the development of the market, guiding the selection of service projects in the process of community work, the development of standards, etc.; 
Normative functions Leads the market's healthy competition and development, and coordinates the relationship between the enterprise and the interest groups. Especially when the community serves as the main body, the relationship between the community and other service providers;

Governance function refers to the market when the obstacles encountered, government from the public welfare perspective of public services to do public service governance,

To do not meet the standards of the integrity of the main body to be eliminated;

Service function, on the one hand, requires the government to provide specific and detailed service standards, analysis of the actual capacity of the community to undertake, and reasonable to do a good job in the supervision of public services and other public services. On the other hand, for those the market cannot do or should not do, do not want to do the project, the government should perform the service functions, the initiative to provide services;

Management functions is that when necessary, the government should participate in the operation and management of public services, and introduce international standards, in the comprehensive community service market, the quality of service and grade have also been upgraded.

\section{The Model Design of Community Service Marketization Development}

In order to improve the quality and efficiency of public service, Combined with the functions of the government in the process of community service market, this paper constructs the $5 \mathrm{M}$ model of community service marketization, as shown in Fig. 1.

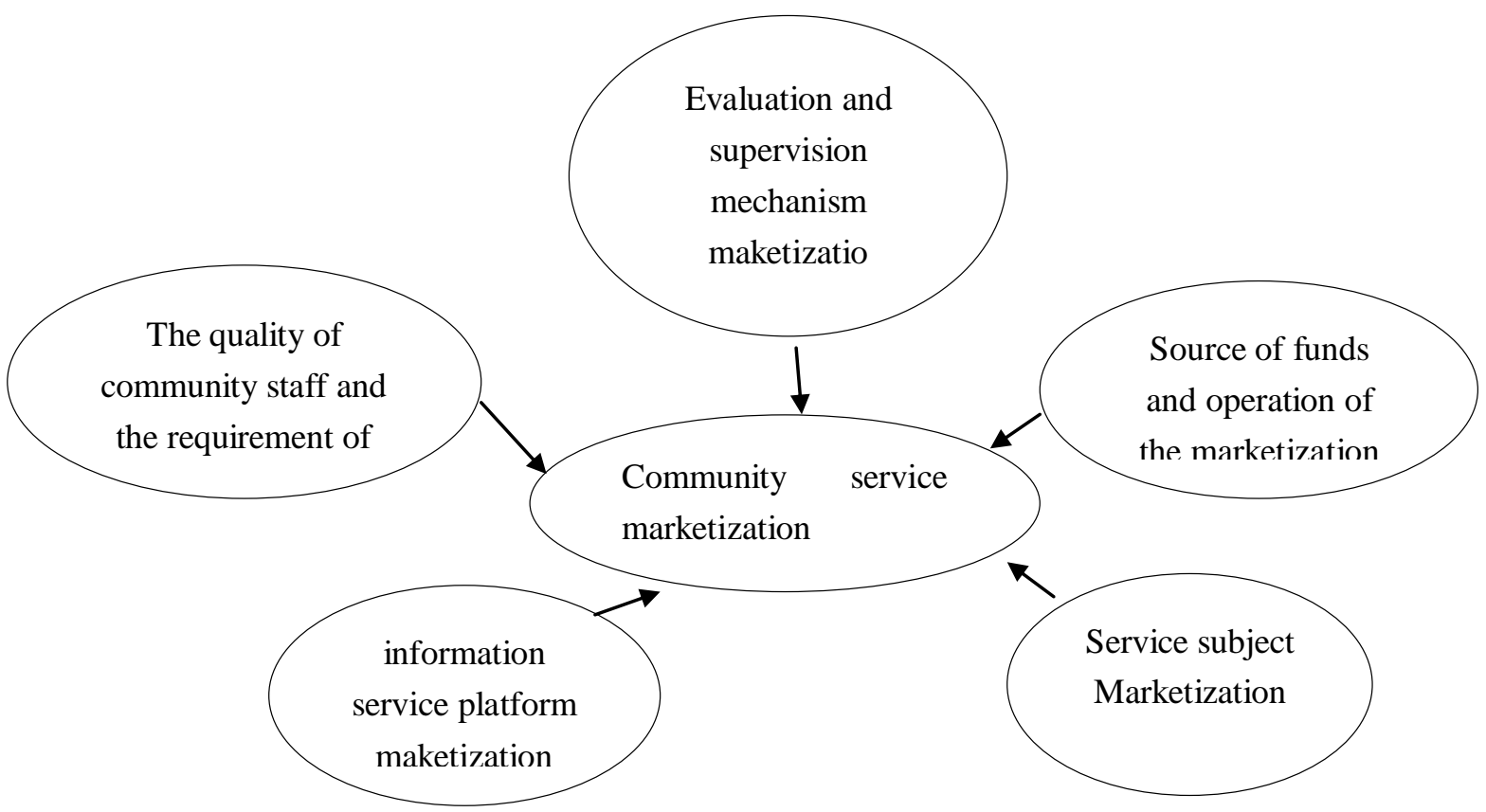

Figure 1. 5M model of community service market

Marketization of Service Subject. In terms of service subject, The government should be authorized to be greater than the centralization of power, allowing the community to decompose the service project according to the characteristics of the area, To identify items that can be purchased from social organizations under the coordination of the government, and the community is responsible for the coordination and implementation, so that the community governance to achieve the situation of multiple participation in service.

At present, the urban community service in many aspects is not enough professional, and social organizations came from the community, rooted in the community, closer to the people, Some organizations have professional skills and human resources, will provide more professional services. In particular, the service providers can achieve the effective combination of government funds and 
social organization resources and efficient use, and realize the transformation of community service from administrative to market.

Service Funding Sources and Operation the Marketization. For the community funding problem to run, can be divided into three parts. First of all, the government can provide the minimum standard operating funds for the maintenance of grassroots organizations, to ensure that the basic operating costs of the community; The community's the service income of compensation and low compensation part is the second part of the community funding sources, Community need to integrate their own power or cooperate with social organizations to provide some services, getting part of the income of funds; The third part of the source of funds is the social groups and individuals to donate, the community should establish a corresponding registration, use system, and based on these sources of funds to adjust the scope of service projects in a timely manner.

The government's financial support to the public service market should be put in a lot of public budget, Can provide tax relief or other preferential policies for enterprises to provide public service projects, Such as to carry out the family pension service units to provide bed support, to solve the employment of the disabled enterprises to provide tax relief and policy support, etc.; The government should also arrange for purchasing funds according to the catalogue of the service,

For new needs arising from changes in demand, to consider increasing the scope of service purchases, and all the information to the public, On the one hand, prepare for the follow-up work, on the other hand, also accept the supervision of the community, to enhance the community's attention and participation of community service.

The Management of Community Workers and the Quality Requirements of the Marketization. To improve service quality, it is necessary to enhance the ability and quality of community workers, learning from the experience of social training institutions, to carry out regular, professional training. At present, the number of community workers cannot meet the needs of a variety of services, members of the level of difference is very large, even if it is to accept the training, the effect is uneven, far from the market demand. So it is necessary to the relevant departments to raise awareness, strictly with system, the timely formulate of standards for selection and appointment of the community workers, in accordance with the requirements of market-oriented training, to ensure that after the training of personnel to be able to feel at ease in the job.

Can also play the role of community volunteers, volunteers, such as the role of the main body of public welfare services, or with the opportunity to fully play the role of Party members into the community activities of Party members, to provide more diversified professional services for community development, but also to help solve the problem of the number of community workers.

Information Service Platform Construction Marketization. The intelligent community construction should be put into an important work, around as the community service development goal to establish a web site for the operation of the community service platform for the integration of public service platform, with the main features of the times, coordination, public welfare and welfare, Integration the social resources that can provide a variety of services to, adhere to the combination of centralized and decentralized mode of operation and control platform system, to establish a network center in line with international standards.

The community should arrange for someone to be responsible for the operation and maintenance of the website, to register the service request, to arrange the service, Unified by the community responsible person, to achieve the presence of community service or on-site service combination. The construction of information platform not only refers to the network service platform, but also includes telephone number, information assistant, and other artificial information network. The role of the government is to monitor the quality and scope of services, with the community to do a good job of producer services organizations, looking for service providers, to coordinate supermarkets, distribution, health care, transportation and other aspects of the work.

Evaluation and Supervision Mechanism of Marketization. Establish the dynamic evaluation management and supervision mechanism for the implementation process of the service project, set up a special organization responsible for the supervision of the government procurement of public 
services, On the government purchase, from the project selection, application, review, project, tender, contract, implement, knot, evaluation and feedback, etc., to improve the dynamic management approach, improve the relevant laws and regulations and policies. The legitimacy and effectiveness and implement effect the government for the service supply should be strictly controlled, to achieve the functions of guidance, standardization, management, etc.

The government choose to undertake the social organization for a variety of services, should consider whether the organization has enough team executive personnel, whether can have enough time and energy, what is the advantages of institutions, whether the financial system is sound, whether the norms of management, whether the project completed on time and durability, whether to have the psychological welfare rather than the pan Market Orientation and.

In the implementation process should pay attention to the purchase agreement in accordance with the time and place to provide services, the development of project funds for the financial management of special accounts, to implement the third party audit system, according to the audit results to pay costs; Establishing the third party evaluation mechanism, requires all the organization to undertake the project to accept a unified arrangement of the project assessment, to eliminate utilitarian behavior and contrary to the integrity of the practice, and to take the performance of the agency into Credit system, Through the information platform and the government network sharing of credit records to evaluate the next time the agency has the right to undertake the project.

In short, the government should make clear the function and status of community service, so that the function of community can be further decomposed and transferred, Government agencies should change from the public service provider, producer and supervisor of the synthetic a dominant position to service providers and supervisors, offering producer status to the social organization. Government administrative from one direction transform to the development mechanism of two-way interaction in the combination of government, market and social organization.

\section{Acknowledgements}

Fund Project: National Social Science Fund project, Study on the pattern innovation of grass roots party building under the rule of law in the field of law (15BDJ021);

The periodical result of the research center of economic and social development, Dalian University

\section{References}

[1] Wang Puqu, [America] Leicester M Salamon. The government's purchase of public services to social organizations-China and the global experience analysis [M].Beijing: Peking University press, 2010.

[2] Rao Huilin. Chinese city management [M].Beijing: Economic Science Press, 2003.

[3] Zhou Zhiren. Correctly understand and strengthen the market mechanism of public service [J].Study and exploration, 2010 (1). 